\title{
Essay Review of
}

William L. Harper, Isaac Newton's

Scientific Method, Turning Data into

Evidence about Gravity \& Cosmology,

Oxford University Press, 2011

Steffen Ducheyne, The Main Business of Natural Philosophy, Isaac Newton's Natural-Philosophical Methodology, Springer, 2102

\section{Niccolò Guicciardini}

Università degli Studi di Bergamo

The years 2011-12 will be regarded as memorable ones for the "Newtonian industry" since they have witnessed the publication of two beautiful and long awaited books devoted to Newton's method and philosophy. They deserve great attention and praise, and I warmly recommend them to any reader interested in 17th and 18th century science and philosophy. The favorable conjunction of 2011-12 should not come as a surprise for those who have been following the recent trends in Newtonian scholarship. Indeed, after the great generation of H. W. Turnbull, A. Koyré, I. B. Cohen, D. T. Whiteside, B. J. T. Dobbs, A. R. Hall, Mary Boas Hall, and R. S. Wesftall, Isaac Newton has continued to be the object of intense historical research. In the 1990s, a new wave of historians of mathematics, who capitalized on the immense riches of Whiteside's edition of the Mathematical Papers (1967-1981), produced a flood of essays devoted to rather technical aspects of Newton's oeuvre. An incomplete list includes Michel Blay, Dana Densmore, Herman Erlichson, Bruce Brackenridge, François De Gandt, Bruce Pourciau, and Michael Nauenberg. ${ }^{1}$ Now the pendulum seems to be swinging towards philosophy, rather than mathematics, as is immediately apparent from the titles of the two books under review. The focus of Harper and Ducheyne's books is Newton as the originator of a new method-an alternative and more effective method than the hypothetico-deductive one.

1. See, for example: Blay 1992, Brackenridge 1995, Herman Erlichson 1994, Nauenberg 1994, De Gandt 1995, Pourciau 1992 and Pourciau 1998, Densmore 1995. 
In what follows I will not have the space to delve into all the details of the books under review: such a task would require one to exceed even the generous word limit granted by Perspectives on Science. What I will try to do is to provide the reader with an account of the main theses defended in these books by framing them within the context of their respective interpretative traditions. In the closing paragraphs I will attempt to suggest new historiographical approaches that might complement what has been achieved by Harper and Ducheyne.

Harper's aim in Isaac Newton on Scientific Method is to provide a systematic and comprehensive treatment of Newton's argument in support of the idea of universal gravitation, based on a combination of accurate experimental and observational results $^{2}$, mathematical inferences ${ }^{3}$ and epistemological assumptions ${ }^{4}$. Newton's starting point is the notion that the familiar force of gravity that acts close to the Earth's surface is, in fact, a long-range force responsible for the motion of primary, secondary planets, and comets, the ebb and flow of tides, as well as for the shape of planets. Part of the problem with Newton's argument is that in order to capture its cogency one has to read the Principia from cover to cover. Indeed, in the Principia there is no single argument, but a complex handling of mathematical models which are confronted with experimental data. The mathematical sophistication of Newton's work and his stringent demand for accuracy were unprecedented in his times. As Harper shows, there was something new in Newton's way of handling models and measuring theoretical parameters. Previous natural philosophers, such as Galileo and Huygens, had followed what might be called a hypotheticodeductive method, whereby a hypothesis is tested by comparing predictions drawn from it with experimental data. If the predictions are accurate enough, the hypotheses can be considered corroborated, whereas small deviations between prediction and observation can be attributed to disturbing factors. As I. B. Cohen, and later George Smith, have demonstrated in great detail, Newton proceeded differently (Cohen 1980 and Smith 2002). Harper puts it as follows: "Newton's treatment of these deviations exemplifies a method of successive approximations [. . . ]. On this method, deviations from the model developed so far count as new theory-mediated phenomena to be exploited as carrying information to aid in developing a more accurate successor" (p. 6). Typically, the deviations from Keplerian motions exhibited by planets are interpreted as due to gravitational perturbations exerted by masses distributed in the solar system, masses that

2. Most notably, the phenomena that open book 3 of the Principia ( $3 \mathrm{rd}$ ed.).

3. A number of propositions in book 1 .

4. Most notably, the four regulae philosophandi in the Principia ( $3 \mathrm{rd} \mathrm{ed}$.$) .$ 
can be identified as causes of perturbing gravitational forces. It is the success of this identification, along with the unfolding of more and more accurate models integrating new details of the planetary system that constitutes the main achievement of Newton's Principia. This is a well-known feature of the Newtonian method that, as I mentioned above, has been studied by Cohen and Smith in great historical and philosophical detail. What is new about Harper's book is his careful reconstruction of Newton's argument for gravitation expounded in the first eight propositions of book 3. Any scholar interested in understanding Newton's Principia should be grateful to Harper for his accomplishment.

Harper aims to reconstruct a cogent argument for gravitation from the text of the third edition of the Principia. How did Newton select and handle the numerical data that constitute the phenomena that open book 3 of the Principia (bearing in mind it is the $3 r d$ edition that Harper is analyzing)? How did Newton deploy the mathematical propositions of book 1 in order to demonstrate that planets are deviated from rectilinear inertial motion by a central force directed toward the Sun, and that the intensity of this force varies inversely to the square of the distance? How did Newton come to identify this force with gravitation? On what grounds did he claim that this force, governing planetary interactions, extends its action to all bodies in the Universe? Harper delves into these thorny questions with authority and expertise, and in so doing clarifies many enduring puzzles. For example (on pp. 220-47), he critically discusses Westfall's claim that Newton fudged his lunar data in order to achieve an extraordinarily precise agreement with Huygens's data on pendulum motion close to the Earth's surface; data that are necessary to claim that the Moon is accelerated by inverse-square terrestrial gravity (Westfall 1973). In this instance, we find an illustration of an important feature of Newton's methodology that Harper often underlines: the progress made in the accuracy of the succession of mathematical models that approximate observed phenomena is measured on the basis of the increased accuracy of the measurement of theoretical parameters such as the constant $g$ extracted by Huygens's pendulum experiments. As Harper rightly observes, it was the agreement between different measurements of theoretical parameters obtained by experimental data concerning different phenomena that ensured the empirical success of Newton's theory of gravitation. This is still an important feature of the methodology of theoretical physics today: we need only consider the corroboration lent to the Standard Model by increasingly accurate measurements of the Weinberg angle in independent experiments in which different particles and widely separated energy ranges are involved (Amsler 2008).

What makes the third book of the Principia difficult and fascinat- 
ing to read, is the plurality of experimental and observational data that Newton takes into consideration in order to corroborate-by successive approximation - the parameters of his celebrated theory, such as, for example, the ratio between inertial and gravitational mass. Harper's book will be of great help to all readers interested in orienting themselves in the daunting world of Newton's handling of data.

Harper's book, it should be added, is extremely difficult to read. The author does not make too many concessions to his readers and asks them to proceed through his pages equipped with paper and pencil. It seems to me that the readers who will profit the most from Isaac Newton's Scientific Method are philosophers of science interested in studying the details of how a theory can receive evidence from experimental data. Newton, the seventeenth-century natural philosopher, and the Principia, a text situated in a specific context that determined its meaning for its author, receive little attention from Harper. As I stated above, the Principia are examined in their third (1726) edition, and only the first propositions of book 3 are the object of Harper's analysis, because it is there that the argument for universal gravitation is to be found. What might be even more worrying for some historically minded readers is Harper's free use of mathematical techniques not available to either Newton or any of his contemporaries. There is nothing wrong, I concur with Nicholas Jardine, in using techniques not available to the historical actors: we should not limit our analytical tools because of a purist concern about anachronism (Jardine 2000). In a way, the use of conceptual resources not available to historical actors is unavoidable; it is an essential part of historical interpretation. When reading Newton, we can and must use mathematical techniques not available to him, provided that we are aware of the dangers of historical distortion implied by such usage. I think that most of the time Harper has done a nice job in alerting his readers about the modernizing effects brought about by modern terminology and techniques. Most notably, he makes perfectly clear that in Newton's times even the taking of the arithmetic mean from a set of data was unusual. Actually, statistical examination of observational data began only in the eighteenth century, and Newton was a pioneer in averaging data, as Buchwald and Feingold have discussed at length (2012, pp. 92-101). However, I think that Harper's use of statistical analysis has projected on Newton's procedures a quantitative precision that is so often lacking in book 3 of the Principia. Typically, by statistical analysis of data cited in Principia, Harper derives a t-Student quantitative estimate of confidence intervals; however, quantitative tests of this sort are remote from Newton's mathematical practice. Newton's method, as already remarked above, is based on the use of approximate models, yet Newton is seldom able to quantitatively control 
the level of approximation, and therefore make use of the precision of Harper's statistics. For example, when he models planetary motions in terms of "orbits that differ very little from circles" (prop. 45, book 1), we are not told what "nearly" means, or how such an approximating assumption affects the level of accuracy of inferences drawn from it. ${ }^{5}$ Indeed, the introduction of a calculus-based approach to planetary perturbations, thanks to the work of Clairaut, Euler, and d'Alembert (among others) at the mid of the 18th century was motivated by the possibility that calculus offers to keep the level of approximation under quantitative control-for example, by expanding orbital parameters as power series of the eccentricity and systematically truncating the relevant series after an explicitly specified power. From this point of view, Harper's approach does not put into relief the significance of an important change in the mathematization of analytical dynamics that occurred just after the third edition of the Principia was published, a change that certainly made the mathematical methods deployed in Newton's masterpiece obsolete.

Further, in some cases considered in Harper's book, the application of the Student's t-distribution appears problematic. For example, on pp. 181-6, Harper considers the empirical success of the celebrated moontest. The data in this case are those obtained in different experiments by Picard, Huygens, Richer, and Varin et al., who provided four seconds pendulum estimates of the one second's fall $d$ at Paris; and those obtained by Prolemy, Vendelin, Huygens, Copernicus, Streete, and Tycho, who provided six estimates of the lunar distance from the earth in terms of earth radii. Harper applies a Student's t-confidence estimate to these two sets of data. The Student test should be carried out under the assumption that the (statistically independent) observational data (four for the first set, six for the second) are extracted from the same Gaussian population: that is, one assumes that they have the same true mean and the same (unknown) true variance. ${ }^{6}$ Typically, one assumes that the same experimental proce-

5. Another example of Newton's qualitative approximation is prop. 26, book 3, where we read: "let us imagine that the orbit [of the Moon] is circular, and let us ignore all inequalities with the sole exception of the one [the so-called "variation"] under discussion here." (Newton 1999, p. 841). As Wilson observes, Newton did not deduce the Moon's orbit from the equations of motion, as Euler did, but, rather, "assumed a fictive shape (a concentric circle) and reasoned to the modification in it that the perturbing forces would require." (Wilson 2001, 171).

6. There are cases in which a suitably modified Student's test is applicable also in the presence of unequal variances, yet this aspect is not, and probably cannot be (given the quality of the data examined in Isaac Newton's Scientific Method) discussed by Harper. Further, the effect of departures from the Gaussian assumption can be minor in certain circumstances. So, in principle, the intervals given by Harper could be close enough for the argument he is pursuing. I thank Alberto Rotondi (Department of Physics, University of 
dure and apparatus are used in taking the data. In the case at hand the data (e.g., the four data concerning seconds pendulums estimates of $d$ ) have, one presumes, the same mean, but different variances, as it should happen with different experiments (those of Huygens, Picard, Richer, and Varin). Yet, nothing is said about the errors of the data taken in the four different experiment cited above, or about the sample sizes, presumably because what Newton had access to were just four "golden numbers" provided by Huygens, Picard, Richer, and Varin, who-as usual in those times-did not publish the set of their experimental data, but rather a single value that they chose as the best amongst their results. Therefore, it seems to me, Harper's application of the Student's t-confidence estimate is not entirely rigorous.

With Steffen Ducheyne's book we are in an altogether different research tradition compared to that of Harper, who is deeply indebted to the historiographical approach brilliantly championed by Howard Stein. The theme is, again, Newton's method, but the author's viewpoint is much broader compared to Harper's — as he takes into consideration not only the Principia, but also the Opticks and some theological worksand solidly anchored to that current of historical interpretation that gives pride of place to a contextualized reading of past actors' language. Ducheyne's book is notable for its extensive and accurate transcriptions and subtle interpretations of Newton's manuscripts, which serve the purpose of illuminating aspects of Newton's thought that come across as opaque, or are just obliquely referred to, in the printed text.

This important difference notwithstanding, Ducheyne is clearly indebted —as he generously recognizes - to Harper's work, and even more so to I. B. Cohen's and George Smith's. Especially in the two chapters (2 and 3) devoted to the Principia, Smith's ideas, and even technical terminology, are clearly discernible. Ducheyne accepts most of Smith's theses

Pavia) and Roger Purves (Department of Statistics, University of California, Berkeley) for their advice on this issue.

7. I note a non-fatal, but worrying, mistake on p. 313 , note 37 where we read: "So a body moving according to an inverse-square force directed toward a center will move in either a hyperbola, or a parabola, or an ellipse with respect to that center. A hyperbolic trajectory would after closest approach to the sun carry the body off into space. A parabolic trajectory would crash into the sun. The only conic trajectory corresponding to a body maintaining an orbit about the sun is Kepler's ellipse" (my italics). Of course, a parabolic trajectory will not necessarily make the body crash into the sun, being one of the admissible solutions for the two-body problem, as Newton proved in propositions 13 and 57-63, book 1. Newton further considered parabolic trajectories for comet motion at the very end of book 3 . 
concerning Newton's method, but he shows maturity and independence of judgment in several ways (he has no qualms, for example, in correcting the classic (Cohen 1980) on pp. $62 \mathrm{ff}$.).

Ducheyne opens his book with a chapter in which he argues that Newton's famous statements on the use of analysis and synthesis in natural philosophy should be read by taking into consideration his youthful studies of Aristotelian textbooks such as Samuel Smith's Aditus ad logicam (1649). ${ }^{8}$ According to Ducheyne, Newton creatively made use of the terminology and conceptions characteristic of the Aristotelian tradition, and most notably of the book by Smith he owned and-as Ducheyne discoveredannotated. Some of Newton's pronouncements on the method of analysis and synthesis can be interpreted as meaning that in the method of analysis one deduces forces from phenomena (most notably, trajectories), while in the method of synthesis one deduces phenomena by assuming forces to be known. Aristotelian textbooks make a similar distinction between two stages in the inquiry of nature, one in which proximate causes (first in the order of nature, but second in the order of knowledge) are inferred from phenomena, the other in which phenomena (first in the order of knowledge, but second in the order of nature) are deduced from their causes.

In chapters 2 and 3 Ducheyne moves on to analyze the Principia. He devotes great attention to the genesis of Newton's masterpiece, to the mathematical methods deployed, to Newton's methodological pronouncements concerning method and how they fit with his actual scientific practice. The overall thesis confirms what Cohen, Smith and Harper have argued: Newton's method is not the hypothetico-deductive method, but rather a more complex and stringent one, which yields greater evidence thanks to a progressive refining of mathematical models.

Next Ducheyne moves on to examine Newton's optical work, which he considers to be characterized by a failure to successfully implement the method of the Principia. More precisely, Newton was unable to "accommodate optical phenomena according to his own methodological ideals" (p. 179), as expressed in his Principia and in related manuscripts.

8. These passages occur in Query 31 of the Opticks — but also see the very interesting manuscript which is transcribed by Ducheyne on pp. 50-2 (CUL Add. MS 3968, f. $109 \mathrm{r}-\mathrm{v})$. It should be noted, however, that this manuscript does not seem to support Ducheyne's thesis concerning an Aristotelian influence on Newton's discourse on analysis and synthesis. When referring to analysis and synthesis in the manuscript, Newton clearly refers (as could be proved by collating these lines with manuscripts in which Newton comments Pappus's work) to the seventh book of Pappus's Collectio: he describes the analysis and synthesis of the "Geometria Veterum," and then relates these methodological distinctions of the double method of analysis and synthesis characteristic of Greek geometry to his own "Methodus Synthetica fluxionum et momentorum" (p. 50). 
Ducheyne points to several "asymmetries” between Newton's mathematization of gravitation and his treatment of optical phenomena. Most notably, in the former case Newton was able to establish causal relationships as systematic dependencies between cause and effect (without committing himself with regard to the physical nature of the interaction responsible for such dependencies), while in the latter he wished to provide an account of optical phenomena (say, the constitution of light, or interactions between light and matter) that had to be framed in hypothetical physical terms (one might think of Newton's account of the color of thick plates in terms of the interaction between ether waves and transparent corpuscles constituting matter (Shapiro 1993).

In the final chapter, Ducheyne considers the interaction between Newton's natural philosophy and theology. He bases this chapter on a thorough analysis of the General Scholium that concludes the second edition of the Principia: he analyzes the printed text as well as often extremely interesting manuscripts related to it. Ducheyne shows that Newton conceived his natural philosophy of gravitation as a means to reject certain aspects of Descartes' and Leibniz's philosophy—such as soul-body dualism, determinism, the autonomy of Nature from God's providential actionwhich he despised on theological grounds. On the other hand, Ducheyne quite convincingly argues that it is misleading to see-as (Mamiani 2002) does - a deep continuity between Newton's method in natural philosophy and the method he deployed to decipher prophecies. Further, Duchyene observes that while Newton's conceptions of space and time were certainly influenced both by his physics and by his theology, it seems that he was able and willing to keep these two levels of discourse separate: in the scholium on space and time which follows the definitions "Newton consciously restricted himself to technical arguments" (p. 274), since he was addressing a matter that could be dealt with independently from theological issues.

As it is apparent from the brief account above, Ducheyne's book offers quite a rich account of Newton's thought on method: its author treats authoritatively and in an innovative way many themes that have long been a central focus of attention in Newtonian scholarship. This is a book that will remain an indispensable reference for future historical research on Newton's natural philosophy. It should be added that Ducheyne conceives his book not "as a contribution to Newton scholarship or Early Modern Science alone, but also as a contribution to the History of Scientific Methodology": that is, as a historical study of the "practices and convictions about how to obtain knowledge about the empirical world" (p. 302). As such, this book will be of great interest also to philosophers of science.

The books under review demonstrate the importance of Newton's 
achievements for the development of philosophy. Andrew Janiak has argued in favor of looking at Newton as a philosopher in a most powerful and convincing way in his pivotal book. Here he claims that Newton "did not present a philosophical system [. . . ] an overarching theory of knowledge or response to global skepticism", but instead "dealt systematically with those elements of metaphysics that are intimately connected with his work in mathematical physics" (Janiak 2008, p. 9). Janiak and Eric Schliesser have recently claimed that Newton can be regarded as one of the leading figures in the development of philosophical ideas for at least two reasons: first, because "Newtonian mechanics" came to be seen as a "privileged form of knowledge" to be engaged with in metaphysical and epistemological discourse; and second, because philosophy came to define itself "in terms that often contrasted with-or were modeled onNewtonian success" (Janiak and Schliesser 2012, p. 1).

Newton, it should be added, had a very complex persona: studying his work means confronting daunting philosophical problems, but also getting to appreciate an extraordinarily rich scientific practice, which spans from experimentation to pure mathematics. Newton is known as the author of metaphysical tracts such as the so-called De Gravitatione, yet he was also a craftsman who was able to build the first reflecting telescope-an achievement which secured him a fellowship at the Royal Society, and which would have lain well beyond the competences of an Immanuel Kant or a Karl Popper. Newton was appreciated by his contemporaries for his dexterity as an artisan and a technician able to handle metal alloys and optical devices, biblical concordances and astronomical computations: when reading his correspondence, one finds that he was often consulted (most famously by Halley in August 1684) because of his skills in answering thorny technical questions. Newton was proud of the effectiveness of the methods he had devised in the laboratory as an optician, chemist and physicist, and at his desk as a chronologist, interpreter of alchemical and biblical texts, and geometrician. And I wonder to what extent Newton's pride in being the discoverer of such efficient methods lies behind the contempt for metaphysics which informs his scientific as well as theological thought. This resonates with his derision of Descartes and Leibniz and his disdain for "Platonists," who-in the company of the Egyptians and other Heathens- had corrupted the ancient religion with philosophical fancies about the Trinity instead of remaining true to the humble method of the philologist who "hold[s] fast the form of sound words" (Yahuda MS 15.1, f. 11r). Even when Newton broached metaphysical issues, he did so-as Janiak and Schliesser remark in the above-quoted essays - from the standpoint of the practitioner of geometry and mechanics: is De Gravitatione, the most metaphysically significant of Newton's 
writings, not a treatise devoted to hydrostatics, the most Archimedean of disciplines? Newton the metaphysician embedded his speculations on void, space, time, matter, motion and God within a treatise whose literary genre was that favored by hydraulic engineers. We should, I suggest, not only devote our attention to what Newton wrote, but should also be more attentive to the style in which he expressed his ideas. The books under review do not pay much attention to the literary genres that the author of Principia adopted. Yet, Newton communicated his ideas by having recourse to a rich palette of literary strategies that sometimes determine the meaning of his pronouncements. Why was Newton restricting the circulation of some of his work to a close group of acolytes? And how did he position himself within a circle of disciples? How did he choose his correspondents, and what did he reveal to them? What did he allow to go to the press and why? How did he define himself as an author? Why were some of his books (the Opticks and the Arithmetica universalis) and papers (the paper on the brachistochrone in the Philosoophical Transations for 1697) published anonymously?

All these questions concerning Newton's authorial strategies and the context in which Newton proffered his utterances on method are not addressed by Harper and Ducheyne. These two authors are interested in extracting a doctrine on method from Newton's pronouncement and his scientific practice. Thus, they write-and they do so with impeccable professionalism - in the dry style of analytic philosophy. Yet, an image of Newton does emerge from their work-very much as a literary construct. It is an image that is not so much revealed by their historical analyses as premised in the form of a working hypothesis that guides their research. Briefly, this image is that of Newton as a thinker deeply engaged in methodological questions concerning experimental method, metaphysics and epistemology. As I mentioned above, Harper and Ducheyne frame their analyses of Newton's contribution to scientific method in close association with Newton's scientific practice. I very much enjoyed this viewpoint that informs Harper's detailed study of the handling of astronomical data in book 3 of the Principia, as well as Duchyene's careful reading of Newton's manuscripts related to the Principia and Opticks.

The first step that I suggest in order to complement Harper's and Ducheyne's achievements is to bring into the narrative Newton's mathematical as well as alchemical practice. I am not an expert on Newton's chemistry or alchemy, but it seems unsatisfactory to me that in the books devoted to Newton we are reviewing barely a word is spent on these experimental and theoretical pursuits, which absorbed so much of his time and energy. Newton-I would venture to say-did not have the outlook of an armchair philosopher, but rather that of an artisan getting his 
hands dirty in a smoky "laboratory." When working in his rooms, he would spend most of his time consulting astronomical and logarithm tables, drawing curves with instruments of his own make, and performing lengthy calculations. At a certain moment in his life, books such as Mede's one on chronology, Villalpando's one on the Temple, and Spencer's one on the customs of the Jews, together with histories of the early Church and other books on theology, mythological emblems and prophecy, began to encumber his table. Newton's work in these diverse domains was indeed characterized by a "method," or perhaps we should say a "style." Most prominently, in the fields of mathematics and alchemy, Newton gave pride of place to problems and very concrete questions such as: How can one find the radius of curvature of the cissoid? How can one determine the path of a comet? How can one measure the distance of a star? Which mechanism explains the contraction of muscles? What is the regulus stellatus and how can one produce it? Newton's approach to these questions very often revealed a great inventiveness and creativity, a lack of interest - or even contempt-for verbose metaphysical and theoretical setups (like the ones preferred by Isaac Barrow in his lengthy Lectiones Mathematicae from 1683), and a search for practical and efficient techniques to answer very specific questions. His approach was often that of the practical-minded artisan, who will value a method if it works, rather than that of the purist methodologist. Newton might be described, I suggest, as a practitioner for whom what mattered was what one can find at the bottom of the crucible, or as the bottom line of a calculation. What Newton was interested in, what he was good at, was efficiently solving problems that baffled his contemporaries.

Newton the practitioner was particularly efficient in the field of mathematics. His techniques in disposing of mathematical conundrums were spectacular. Driven on by his exceptional mathematical dexterity since his youth, Newton approached mathematics as his calling - as an intellectual enterprise that it was physically impossible for him to set aside. In order to appreciate Newton's mathematical style, the reader might try do develop $y$ as a power series in $x$ in the vicinity of the origin when $x$ and $y$ are related by an "affected" equation such as $y^{6}-5 x y^{5}+\left(x^{3} / a\right) y^{4}-7 a^{2} x^{2} y^{2}$ $+6 a^{3} x^{3}+b^{2} x^{4}=0$; or the reader might try to construct a mechanical device which draws a conic passing through three given points and tangent to two given straight lines lying on a plane, and then turn to Newton's own solutions. ${ }^{9}$ They are so simple and direct! And at the same time, they often reveal deep mathematical concepts. The style in which Newton presented his mathematical discoveries in his manuscripts, in his corre- 
spondence, and later in his printed works was that commonly used by the geometers, land surveyors, astronomers and table makers of his times. Mathematicians had to produce methods for solving specific problems whose utility for whole classes of practitioners-active in local instrument-makers' shops, on the field as surveyors, or aboard ships as mariners - would be often advertised on the title pages of mathematical books (as in, van Schooten 1646). Methods were ostensively illustrated by examples, rather than deduced from first principles. It is telling that Newton subdivided his mathematical masterpiece, the De methodis serierum et fluxionum, into chapters each devoted to the resolution of a problem: his methods of series and fluxions were explained to the learner through their application to increasingly difficult cases. What the practitioners needed were instruments for curve tracing, devices for drawing tangents and radii of curvature, and tables for squaring curves ("integral tables," in Leibnizian terminology). Newton's methods provided just that, and in abundance. This - to repeat-was a style common in the 17 th century community of mathematical practitioners. It is the style of Barrow's Lectiones geometricae (1670), but not of the Lectiones mathematicae (1683). The latter are a verbose presentation of basic concepts of kinematics, geometry, and number addressed to philosophically inclined readers, or perhaps aimed at impressing university literati in the attempt to defend the dignity of mathematics and thus justify the foundation of the Lucasian Chair: they were not the best resource to be introduced into the messy toolbox of Newton the mathematical practitioner. Of course, Newton was guided by theoretical, philosophical and even theological interests in promoting his mathematized natural philosophy. Yet, he shared with mathematical practitioners a number of interests that can be seen as motivations behind the discovery of the calculus. Did he not write his first treatise on the method of series and fluxions, De analysi per aequationes numero terminorum infinitas (1669), as a response to Nicolaus Mercator's Logarithmotechnia (1668)? And was one of the first applications of the binomial theorem for fractional exponents, which he discovered in 1664-5, not the calculation of logarithms? It is known that Newton calculated logarithms up to 55 decimal places in his youthful studies. Since Kepler's Tabulae Rudolphinae (1627) logarithms were the essential tool for table-making. Newton's discovery of the calculus can be seen as having been motivated, at least in part, by the exigency to tabulate logarithms and trigonometric magnitudes which was top in the agenda of astronomers, mariners, and land surveyors in the England of his times. His contemporaries were aware of this connection and "in January 1681, [when] John Adams was undertaking a survey of the whole of England, the Royal Society requested that Newton furnish Ad- 
ams with technical assistance, and Newton did write at least one letter about the project" (Westfall 2001, p. 335). But Newton's involvement with technological enterprises became even more frequent after his move to London. As Warden (1696) and Master (1700) of the Mint, President of the Royal Society (1703), and member of the Parliamentary Committee for the Board of Longitude (1714), he had many more chances for putting his mathematical and chemical talents in the service not of natural philosophy and theology, but rather of much more mundane aims, such as navigation and the reform of coinage. It seems to me that we have still to integrate the history of Newton's mathematical discoveries, and of the early development of calculus in general, within the current narrative of the mathematization of nature in the long seventieth century, which lately has begun to reveal the fundamental role played by the obscure practitioners populating Taylor and Wallis's biographical dictionaries (Taylor 1954, 1966 Wallis and Wallis 1986, 1993).

In his mathematical work, Newton did devote attention to rather broad conceptual issues — such as the status of infinitesimal magnitudes, or the relationship between algebra and geometry-but always he did so strictly within the context of his mathematical practice. Newton the philosopher of mathematics is indeed discernible behind Newton the busy mathematical practitioner. But trying to understand the former without paying due attention to the latter can produce distortions in the image we achieve of Newton; more precisely, what we would achieve is an image that Newton himself would have disavowed. Indeed, when engaged in the fierce polemic with Leibniz over the invention of the calculus, Newton often underlined that he deserved all praise because he had been able to solve much more difficult problems compared to the German: their mutual confrontation-according to Newton's polemic strategy—concerned results, not first concepts, rules and notations.

Some concluding remarks on the Principia are in order, since this opus magnum is given pride of place in the books under review. My suggestion to approach the study of Newton starting from the assumption that his work could be related to the enterprises of the practitioners listed in Taylor's biographical repositories (see the Newton biography in Taylor 1954, p. 251) seems desperately wrong when we consider such an imposing work, which was presented by its author as a better alternative to the philosophical manifesto of mechanical philosophy. Yet, while it is true that it was in order to disprove Descartes' Principia that many pages of Newton's Principia were written, it is not with metaphysicians that Newton corresponded during its composition; nor did he write the work in emulation of metaphysicians. It is a polymath-Christiaan Huygens- 
that Newton held as his model, and it is with astronomers such as John Flamsteed, Robert Hooke and Edmond Halley that he was deeply engaged while writing it. In the third book, which brings the work to completion, Newton clearly addressed himself to professional astronomers. When wishing to define the readers he was addressing, Newton mentioned natural philosophers well steeped in geometry and astronomy. ${ }^{10}$ What Newton displays in book 3 is an intimate knowledge of the technical issues of astronomical practice, as many pages of Harper's book amply demonstrate. It is this facet-and not just methodological or metaphysical theoretical options - that distinguishes Newton's Principia from Descartes'. The Frenchman, Newton thought, had written nothing but fiction, whereas with book 3 he himself had written an astronomical treatise. Book 3 ended with the mechanical tracing of the parabolic orbit of the 1680/81 comet: a display of craftsmanship illustrating the author's acquaintance with astronomical tables, new insights on interpolation methods, a graphical iterative approximation technique, and the careful handling of tracing devices. I believe it might be fruitful, then, to continue along the lines so clearly traced by Harper by reading Newton's Principia in the light of the astronomical tradition. Newton's method of devising a series of models that increasingly approximate planetary motions by successive adjustments - a feature underlined by Cohen, Smith, Harper and Ducheyne-strikes me as bearing some analogies-despite obvious differences when it comes to the notions of cause and force-to the old traditional astronomical procedure, whereby adjustments would be made to deferent circular motions (eccentric and equant points, major and minor epicycles) in order to predict planetary longitudes. Newton's studies on the Moon's motion culminated in a "theory" (in the traditional Ptolemaic sense of the word) based on a Horrocksian model consisting in a mechanism implying an elliptic deferent and an epicycle (Newton 1702). The fact that Newton had recourse to such an old-fashioned kinematic mechanism has been often described as a failure (Whiteside 1976). Yet, perhaps Newton the practitioner-astronomer was elated with pride rather than struck by "disenchantment" — as Whiteside would put it—by his kinematic device: it was, after all, a useful model that could help generate more accurate Lunar tables. I do not have the impression that Newton

10. "Scribebam ad Philosophos Elementis Geometriae imbutos \& Philosophiae naturalis fundamenta Geometrice demonstrata ponebam. Et inventa Geometrica quae ad Astronomiam et Philosophiam non spectabant, vel penitus praeteribam, vel leviter tantum attingebam”, Newton 1967-1981, vol. 8, p. 450. 
considered his Theoria Lunae as anything less than a great achievement in the advancement of Lunar table-making (Kollerstrom 2000).

The study of Newton's Principia as a work conversant with the methods of mathematical practitioners and astronomers cannot of course be pursued beyond reasonable limits. In general, one cannot study Newton's scientific practice without recognizing that Newton placed his alchemical, mathematical, natural philosophical and astronomical pursuits within broad philosophical agendas. If he kept on experimenting in his (al)chemical laboratory for years, it was in pursuit of an aim whose breadth was unclear to his amanuensis, and is still an open issue for present day historians. Certainly, this aim was philosophical in character. When Newton the mathematician filled pages upon pages of calculations and diagrams, he did so urged by his vocation for mathematical creativeness. Yet, he also had a more ambitious purpose in mind: Newton assigned himself a special place in his own reconstruction of the history of mathematics and held rather passionate views about mathematical method, the superiority of the methods of the ancients over those of the moderns, and the role of mathematical method in natural philosophy. When writing the Principia, religious views about God and his relation to Nature, as well as convictions about the presence of non-mechanical agents in Nature occupied his mind and in part directed his research project, as Ducheyne shows in the final chapter of his book. So in the end, Newton the practitioner was also a philosopher. Yet, I would argue that Newton's philosophical agenda was considerably different, in language and purpose, from what we call philosophy nowadays - or even from what Kant understood by this word more than two centuries ago. The impression I have is that many philosophically informed scholars of Newton's method concentrate their attention on issues that Newton considered within a context considerably remote from the one familiar to the philosopher of science of our day. The viewpoint taken by those who study Newton's ideas on scientific method often restricts the canon of Newtonian texts considered relevant to a handful of loci to which critics return again and again (typically, the Regulae, the General Scholium, the De Gravitatione and the queries). And this is so because "philosophy" is understood from our 21st century disciplinary perspective. Harper's and Ducheyne's monographs help us transcend this narrow perspective. I suggest that a study of Newton's method that might make us move even beyond the horizons of the books under review should include an analysis of activities that absorbed most of Newton's time and energy: for example, the practice of chemistry, the practice of mathematics, or the practices of biblical criticism, the deciphering of prophesies, and chronology. The problems, successes and failures in coping with these 
practices that inform Newton's work should be studied in relation to his philosophical pursuits, provided that "philosophy" is conceived in terms that would have been understood by Newton and to his contemporaries. Otherwise we risk producing an elegant exercise in contemporary philosophy of science that addresses questions that were not a priority for Newton - or which possibly he would not even have understood.

Finally, let me add that in order to achieve a more contextualized understanding of Newton's philosophy and its relation to his scientific practice, one needs to approach his discourse within the linguistic conventions and disciplinary boundaries of his age, which were influenced by the dramatic social, religious and political upheavals that unsettled England during Newton's own lifetime. The above statement borders triviality, yet any reference to the social, religious, political and economic contexts is conspicuously absent in the works belonging to the interpretative tradition in which Ducheyne and Harper so authoritatively position themselves. The purpose of extracting a method or a philosophical doctrine from a selection of Newtonian texts-however comprehensive this selection may-is, of course, a laudable scholarly enterprise, and we should be grateful to the authors of the books under review for having gone so far in fulfilling it. Yet, after reading the dry and often anachronistic prose in which these books are written, I found it refreshing to turn to the "thick description" - as Clifford Geertz would have it (Geertz 1973) — of Newton's ideas provided by Frank Manuel in his delightfully eccentric biography (Manuel 1968). Here, Newton's philosophical and theological ideas appear less clear-cut, less of a "lesson on scientific method" (Harper, pp. 214ff.) and more of a collection of often contradictory utterances that the author of Principia and Opticks proffered driven by ideological idiosyncrasies, passionately endorsed political and religious opinions, and philosophical aims pursued in contrast to his contemporaries. But this, of course, is a different story. After having savored the philosophical acumen of the books reviewed here (which may rightly be described as masterpieces), we shall have to wait for new books, written by differently oriented Newtonian scholars, in order to enjoy a fresh depiction of Newton not as a theoretician capable of developing-as Harper and Ducheyne demonstrate-ideas on method that are still enlightening for contemporary philosophy of science, but rather as a man with his feet firmly planted on the soil of the England of the Commonwealth, the Restoration, the Glorious Revolution and the Hanoverian succession; a man dog-earing More on the immortality of the soul, Mede on the methodizing of prophesies, and van Schooten on the use of geometria organica for the designing of sundials, in search of a natural philosophy which could provide an answer to his own anxieties, rather than to Whewell's, Duhem's or Popper's questions. 


\section{References}

Amsler, Claude. et al. 2008. "Review of Particle Physics-Electroweak model and constraints on new physics.” Physics Letters B 667.

Barrow, Isaac. 1670. Lectiones Geometricae: In Quibus (Praesertim) Generalia Curvarum Linearum Symptomata Declarantur. London: Godbid.

Barrow, Isaac. 1683. Lectiones Mathematicae XXIII. In Quibus Principia Matheseôs Generalia Exponuntur. London: Typis J. Playford.

Blay, Michel. 1992. La naissance de la mécanique analytique: la science du mouvement au tournant des XVIIe et XVIIIe siècles. Paris: Presses Universitaires de France.

Brackenridge, Bruce J. 1995. The Key to Newton's dynamics. Berkeley, Los Angeles, London: California University Press.

Buchwald, Jed Z. and Moderchai Feingold, Newton and the Origin of Civilization. Princeton and Oxford: Princeton University Press.

Cohen, I. Bernard. 1980. The Newtonian Revolution. Cambridge: Cambridge University Press.

De Gandt, François. 1995. Force and Geometry in Newton's Principia. Princeton: Princeton University Press.

Densmore, Dana. 1995. Newton's Principia, the Central Argument. Santa Fe, New Mexico: Green Lion Press.

Erlichson, Herman. 1994. "The Visualization of Quadratures in the Mystery of Corollary 3 to Proposition 41 of Newton's Principia." Historia Mathematica 21: 148-61.

Geertz, Clifford. (1973) 2000. “Thick Description: Toward an Interpretive Theory of Culture”. Pp. 3-30 in The Interpretation of Cultures. New York: Basic Books.

Janiak, Andrew. 2008. Newton as Philosopher. Cambridge: Cambridge University.

Janiak, Andrew and Eric Schliesser, eds. 2012. Interpreting Newton, Critical Essays. Cambridge: Cambridge University Press.

Jardine, Nick. 2000. "Uses and Abuses of Anachronism in the History of the Sciences." History of Science 38 2000: 251-270.

Kepler, Johannes. 1627. Tabulae Rudolphinae. Ulm: Typis Jonae Saurii.

Kollerstrom, Nicholas. 2000. Newton's Forgotten Lunar Theory: His Contribution to the Quest for Longitude. Santa Fe, N.M.: Green Lion Press.

Mamiani. Maurizio. "Newton on Prophecy and the Apocalypse." Pp. 387408, in The Cambridge Companion to Newton. Edited by I. Bernard Cohen and George E. Smith. Cambridge: Cambridge University Press.

Manuel, Frank. 1968. A Portrait of Isaac Newton. Cambridge (Mass.): Harvard University Press.

Nauenberg, Michael. 1994. "Newton's Early Computational Method for Dynamics." Archive for Historv of Exact Sciences 46: 221-52. 
Newton, Isaac. 1669. De analysi per aequationes numero terminorum infinitas. Pp. 206-47 in The Mathematical Papers of Isaac Newton. Vol. 2. Edited by D. T. Whiteside. Cambridge: Cambridge University Press.

Newton, Isaac. 1671ca. De methodis serierum et fluxionum. Pp. pp. 38-328 in The Mathematical Papers of Isaac Newton. Vol. 3. Edited by D. T. Whiteside. Cambridge: Cambridge University Press.

Newton, Isaac. A New and Most Accurate Theory of the Moon's Motion...., Published in Latin by D. Gregory in his Excellent Astronomy. London: A. Baldwin, 1702.

Newton, Isaac. 1967-1981. The Mathematical Papers of Isaac Newton. Edited by D. T. Whiteside. Cambridge: Cambridge University Press.

Newton, Isaac. 1999. The Principia: Mathematical Principles of Natural Philosophy. Translated by I. B. Cohen and A. Whitman, assisted by J. Budenz. Berkeley: University of California Press.

Pourciau, Bruce. 1992. "Radical Principia." Archive for Historv of Exact Sciences, 44: 331-63.

Pourciau, Bruce. 1998. "The Preliminary Mathematical Lemmas of Newton's Principia." Archive for History of Exact Sciences 52: 279-95.

Shapiro, Alan E. 1993. Fits, Passions, and Paroxysms: Physics, Method, and Chemistry and Newton's Theories of Colored Bodies and Fits of Easy Reflection. Cambridge: Cambridge University Press.

Smith, George. 2002. "The Methodology of the Principia." Pp. 138-73 in The Cambridge Companion to Newton. Edited by I. Bernard Cohen and George E. Smith. Cambridge: Cambridge University Press.

Taylor, E. G. R. 1954. The Mathematical Practitioners of Tudor and Stuart England. Cambridge: Cambridge University Press.

Taylor, E. G. R. 1966. Mathematical Practitioners of Hanoverian England 1714-1840. Cambridge: Cambridge University Press.

van Schooten, Frans. 1646. De Organica Conicarum Sectionum in Plano Descriptione Tractatus: Geometris, Opticis, Praesertim Vero Gnomonicis \& Mechanicis Utilis. Leiden: Ex Officina Johannis Elsevirii.

Wallis Ruth V. and Wallis Peter J. 1986. Biobibliography of British Mathematics and Its Applications, Part 2: 1701-1760. Newcastle upon Tyne: Project for Historical Biobibliography.

Wallis Ruth V. and Wallis Peter J. 1993. Index of British Mathematicians Part 3: 1701-1800. Newcastle upon Tyne: Project for Historical Biobibliography.

Westfall, Richard S. 1973. "Newton and the Fudge Factor." Science 179: 751-8.

Westfall, Richard S. 2001. "The Background to the Mathematization of Nature." Pp. 321-39 in Isaac Newton Natural Philosophy, edited by Jed Z. Buchwald and I. Bernard Cohen. Cambridge (Mass.): MIT Press. 
Whiteside, Derek T. 1976. "Newton’s Lunar Theory: From High Hope to Disenchantment." Vistas in Astronomy 19: 317-28.

Wilson, Curtis A. 2001. "Newton on the Moon's Variation and Apsidal Motion: The Need for a Newer "New Analysis." Pp. 139-88 in Isaac Newton's Natural Philosophy. Edited by Jed Z. Buchwald and I. Bernard Cohen. Cambridge (Mass.): MIT Press. 